\title{
Preliminary results of treatment with Intense Regulated Pulsed Light in Dry Eye Syndrome
}

\section{Resultados preliminares del tratamiento con luz pulsada intensa regulada en el síndrome de ojo seco}

\author{
Giuseppe Miotto-Montesinos ${ }^{1,2}$, Eduardo Rojas-Alvarez ${ }^{2,3 *}$ and Diego M. Torres-Piedra ${ }^{2}$ \\ ${ }^{1}$ Medical School, Universidad del Azuay; ${ }^{2}$ Centro Oftalmológico Exiláser; ${ }^{3}$ Medical School, Universidad de Cuenca. Cuenca, Ecuador
}

\begin{abstract}
Objective: To describe the preliminary results of the use of Intense Regulated Pulsed Light (IRPL) in patients with Dry Eye Syndrome due to Meibomian Gland Dysfunction (MGD). Methods: A descriptive, longitudinal and prospective study was performed in 32 patients diagnosed with Dry Eye Syndrome, in which treatment with IRPL was applied between April-December 2017 at the Ophthalmological Center Exilaser, in Cuenca, Ecuador. Three treatment sessions were performed on Day 0, Day 15 and Day 45. Absolute and relative frequencies, Pearson test and Fischer test were used for statistical analyses. Results: After treatment with IRPL, tear film breakup time (BUT) greater than 10 seconds was observed in $87.5 \%$ of the patients, with a correlation between treatment application and a BUT greater than 10 seconds. There was a decrease in the signs observed in the eyelid margin; this decrease was more evident in blepharitis cases. In $81.3 \%$ of the cases, a gentle pressure was enough when performing the gland expression, to obtain a clear liquid in $62.5 \%$ of the cases. All the OSDI test items showed improvement. Conclusions: Our results show an improvement of the clinical signs and symptoms of Dry Eye Syndrome due to MGD after a course of three IRPL sessions over a 45-day period. However, more IRPL studies with a longer follow-up are warranted.
\end{abstract}

Key words: Intense Pulsed Light Therapy. Dry eye. Meibomian gland.

\section{Resumen}

Objetivo: Describir los resultados preliminares del empleo de luz pulsada intensa regulada (IRPL) en pacientes con síndrome de ojo seco por disfunción de las glándulas de Meibomio (DGM). Método: Se realizó un estudio descriptivo, longitudinal y prospectivo en 32 pacientes con diagnóstico de síndrome de ojo seco, en los cuales se aplicó tratamiento con IRPL, durante el periodo de abril a diciembre de 2017, en el Centro Oftalmológico Exiláser, Cuenca, Ecuador. Se realizaron 3 sesiones de tratamiento: día 0, día 15 y día 45. Se aplicaron frecuencias absolutas, relativas, prueba de Pearson y test de Fischer. Resultados: Después del tratamiento con IRPL, en el $87.5 \%$ de los casos se constató un tiempo de ruptura de la película lagrimal (BUT) superior a $10 \mathrm{~s}$, con dependencia entre aplicación del tratamiento e incremento del BUT. Se obtuvo una disminución de los signos encontrados en el examen del borde palpebral, que fue más notoria en la blefaritis. En el $81.3 \%$ de los casos, fue suficiente una presión suave al realizer la expresión glandular para obtener características de líquido claro transparente en el $62.5 \%$ de los casos. Se obtuvo mejoría en todos los indicadores del test de OSDI (Ocular

Correspondence:

*Eduardo Rojas-Alvarez

Federico Proaño 4-26 y Remigio Crespo Date of reception: 02-02-2018

Cuenca, Ecuador

E-mail: drerojasalvarez@gmail.com
Date of acceptance: 19-09-2018

DOI: 10.24875/RMOE.M18000039
Available online: 01-11-2018

RevMex Oftalmol (Eng).2018;92(6):253-259 www.rmo.com.mx

2604-1731/@ 2018 Sociedad Mexicana de Oftalmología. Published by Permanyer México SA de CV. This is an Open Access article under the CC BY-NC-ND license (http://creativecommons.org/licenses/by-nc-nd/4.0/). 
Rev Mex Oftalmol (Eng). 2018;92

Surface Disease Index). Conclusiones: Los resultados presentados muestran una mejora tanto en los signos clínicos y síntomas del síndrome de ojo seco por DGM, después de un curso de tres sesiones de IRPL, durante un período de 45 días, no obstante, se requieren estudios futuros a largo plazo relacionados con este tratamiento.

Palabras clave: Luz pulsada intensa. Ojo seco. Glándulas de Meibomio.

\section{Introduction}

Dry eye syndrome is one of the most frequent reasons for consultation in Ophthalmology, and affects the quality of life of hundreds of thousands of people globally ${ }^{1}$. Every day a growing number of patients go to the specialist seeking to alleviate the bothersome symptoms they suffer, and looking for possible causes and solutions to their discomfort. In most cases, dry eye occurs concurrently with other ocular surface disorders, which makes even more complex the management and resolution of this cases. ${ }^{2}$

The recurrence and high frequency of the symptoms forces these patients to continuously use lacrimal substitutes and, even changing the medication from time to time, searching for new alternatives for their disease, either indicated by the physician or by decision of the own patient.

Throughout the technological development of the specialty, several attempts have been made to mitigate these symptoms and in some way "cure" a chronic clinical entity that on many occasions is presented to ophthalmologists as the patient who "we do not want to consult" or that "has no solution".

Within the treatment options for dry eye syndrome caused by Meibomian gland dysfunction (MGD) is the IPL (Intense Pulsed Light) system, which is a high-intensity light source that emits polychromatic non-coherent light in a broad spectrum ${ }^{3}$.

Unique filters in intense regulated pulsed light (IRPL) limit wavelengths between $550 \mathrm{~nm}$ and $1200 \mathrm{~nm}$ for dry eye treatments, specific for MGD, which is the most common cause of dry eye syndrome. The light is directed to the skin tissue and then absorbed by the target structure, which results in the production of heat $\left(>80^{\circ} \mathrm{C}\right)$ that destroys pigmented skin lesions. Appropriate wavelengths can be selected for different objectives depending on the absorption behavior and the penetration depth of the emitted light, and specific filters can be chosen to limit the delivery of wavelengths to the treatment zone, resulting in a selective thermal supply ${ }^{4,5}$.

The third-generation IRPL device is designed specifically for periocular applications with multiple light pulses homogeneously sculpted (E-Eye, E-Swin, Paris,
France); this is the only medically certified IRPL device to treat $\mathrm{MGD}^{4-6}$. Within its fundamental parameters includes an treatment area of $7.5 \mathrm{~cm}^{2}$ with a wavelength between 580 and $1200 \mathrm{~nm}$, with temperatures ranging from $-5^{\circ} \mathrm{C}$ to $+65^{\circ} \mathrm{C}$.

With the advent of this novel technology to our institution, we began using it in patients with dry eye syndrome due to MGD.

\section{Objective}

To describe the preliminary results of the use of intense regulated pulsed light (IRPL) in patients with dry eye syndrome due to Meibomian gland dysfunction.

\section{Method}

A descriptive, longitudinal and prospective study was performed in 32 patients diagnosed with dry eye syndrome, in which treatment with IRPL was applied between April-December 2017 at the Centro Oftalmológico Exilaser, in Cuenca, Ecuador. There were three treatment sessions at day 0 , day 15 and day 45 .

\section{Criteria for the selection of cases}

Inclusion criteria:

- Patients with dry eye syndrome due to Meibomian gland dysfunction.

- Age: over 18 years old.

- Motivation: for less frequent use of lacrimal substitutes.

Exclusion criteria:

- Black skin (grade VI skin).

- Use of medications that increase photosensitivity.

- Decompensated diabetes mellitus.

- Active skin lesions in the treatment area.

- Pregnancy.

- Skin lesions due to sunburn within one month of treatment.

- Previous history of sun allergy.

- Hemophilia, delayed cutaneous porphyria.

- Pacemaker, defibrillator.

- Epilepsy. 


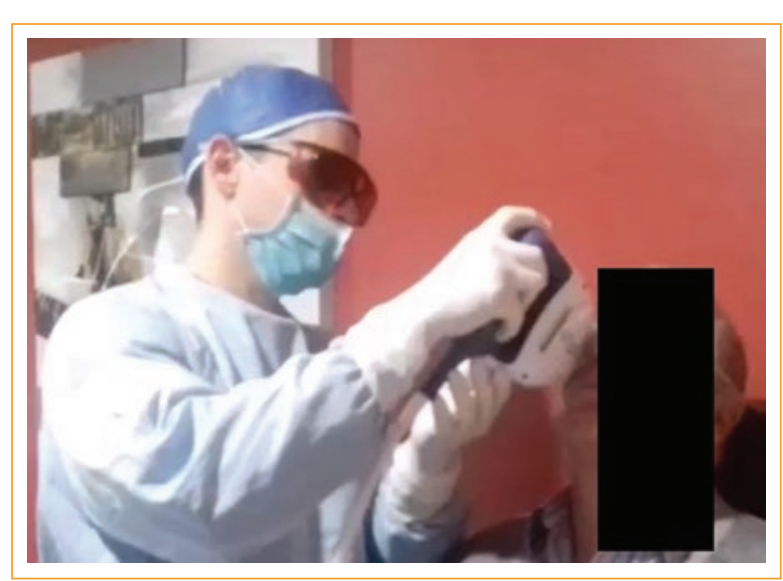

Figure 1. Application of IRPL treatment.

\section{Treatment protocol}

- Cleaning and disinfection of the lower skin region and lateral to the eyeball.

- Closure of both eyes and placement of bilateral occluders.

- Placement of a gel (for conduction) in the treatment area, from the skin of the orbital temporal region, including the skin inferior to the lower eyelids, the region of the nose, up to the contralateral region.

- Application of five flashes, starting in the internal nasal region to the temporal region, in both eyes (Fig. 1).

- Energy level used: $12.2 \mathrm{~J} / \mathrm{cm}^{2}$

- Gel removal from the face and lidocaine instillation (eye drops) (Alcon), one drop in both eyes.

- Slit lamp examination and Meibomian gland expression, previous application of topical anesthesia, with a sterile swab located in the palpebral conjunctiva in the area of the Meibomian gland, while pressure is applied to the skin with the index finger next to the same gland to be explored, for 30 seconds.

- The procedure is repeated in both eyes, in the upper and lower eyelids. The patient should look away from the eyelid that is being examined (Fig. 2).

- Eyelid margin cleaning, specifically of the meibomian secretion obtained.

- Post-procedure:

- Cristaltears ${ }^{\circledR}$ (eye drops) (sodium carboxymethylcellulose $0.5 \%$ ): one drop every $4 \mathrm{~h}$.

- Poenbiotic ${ }^{\circledR}$ (eye drops) (ciprofloxacin 0.3\%, dexamethasone $0.1 \%$ ): 1 drop every 4 hours, up to 5 days after the session.

- Ciprodex ${ }^{\circledR}$ (ointment) (ciprofloxacin $0.3 \mathrm{~g}$, dexamethasone $0.1 \mathrm{~g}$ ): apply at $10: 00 \mathrm{pm}$ up to 5 days after the session.

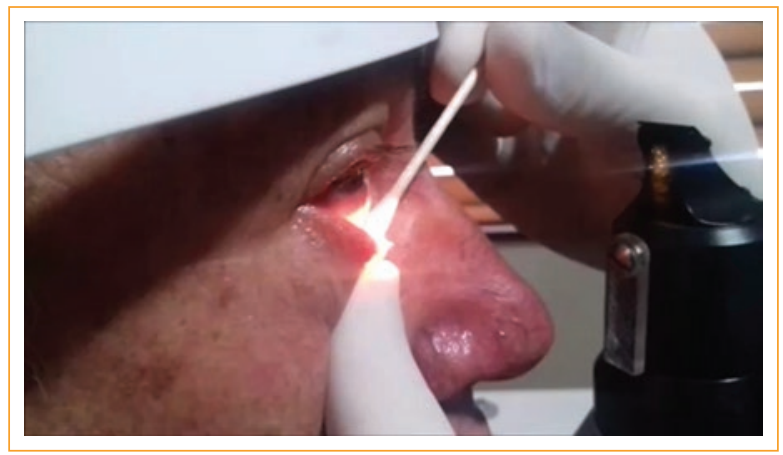

Figure 2. Gland expression after treatment with IRPL.

\section{General characteristics of the technology}

We used the E-Eye technology (E-Swin, France), marketed in Ecuador by SERVICESA (Fig. 3).

Technology: IRPL

Treated area: $7.5 \mathrm{~cm}^{2}$

Dimensions: 345 x 320 x $440 \mathrm{~mm}$

Weight: $11.5 \mathrm{Kg}$

Voltage: $100-240 \mathrm{~V}$

Temperature: $-5^{\circ} \mathrm{C}$ to $+65^{\circ} \mathrm{C}$

Certification: Medical CE, TGA (Australia), WAND

(New-Zealand)

Condition treated: MGD

Wavelength: $580-1200 \mathrm{~nm}$

\section{Study variables}

The following variables were evaluated in two time points: day 0 (before the first treatment) and day

60 (15 days after the third session):

- Tear breakup time (BUT). It was evaluated in a slit lamp with fluorescein and a cobalt blue light, expressed in seconds in the following scale: more than $10 \mathrm{~s}$, between 5 and $10 \mathrm{~s}$, and less than $5 \mathrm{~s}$.

- Signs on the eyelid margin. The presence of irregularity, telangectasias, blepharitis, trichiasis were evaluated.

- Characteristics of gland expression. Evaluated by slit lamp, expressed according to the following scale: clear liquid, cloudy liquid, granular (lumps) and solid (toothpaste).

- Pressure applied to induce gland expression. Pressure applied by the ophthalmologist at the time of gland expression, registered according to the following scale: mild, moderate, severe.

- OSDI (Ocular Surface Disease Index). Questionnaire that includes three groups of questions 


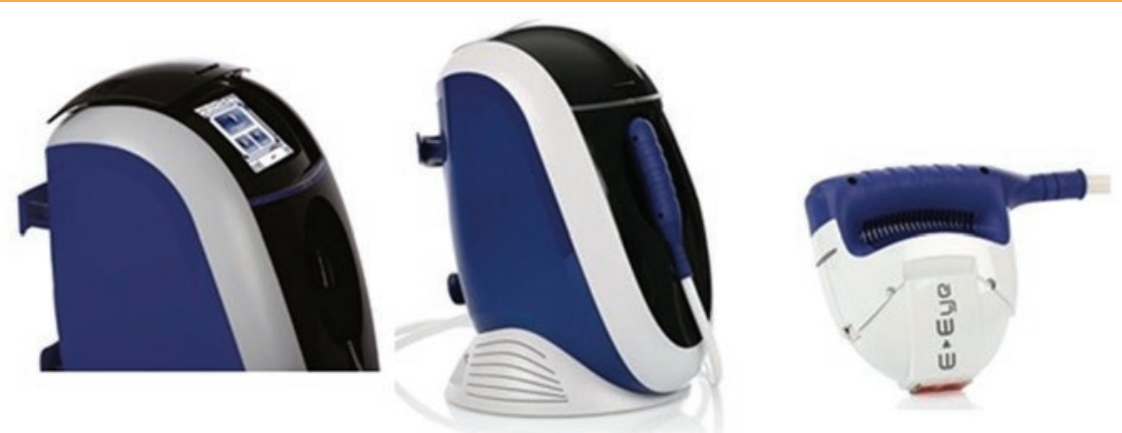

Figure 3. E-Eye technology with IRPL for the treatment of dry eye syndrome due to MGD.

related to the frequency of certain events (symptoms, daily activities and specific situations), where the patient responds on a scale of 0 to 4 with the following categories: 0 , never; 1 , almost never; $2,50 \%$ of the time; 3 , almost always; 4 , always. The questionnaire was applied individually by a professional not related to the treatment application. The value of the mean of the sample was obtained for each category per patient.

\section{Statistical analysis}

The estimations obtained by variable were incorporated into a data table in SPSS ${ }^{\circledR}$ version 21.0. Descriptive and inferential statistics methods expressed in absolute frequencies and relative frequencies were used. A Pearson chi-squared test was applied for a contingency table with the aim of verifying the possible dependence of treatment application (before and after treatment) in the BUT. We then proceeded to analyze the standardized residuals to verify which of the relationships create this dependence. For the variable characteristics of gland expression, a Fisher's exact test was applied. A significance level of $95 \%$ was used. The results were presented in tables and figures. The patients granted their consent for treatment and participation in the study.

I attach Addenda of the Health Care Ethics Committee: Bioethics Exiláser. Authorization - Code: 201803-03. Agreement 3 of 2018.

\section{Results}

As shown in Table 1, before the procedure, most patients had a BUT between 5 and $10 \mathrm{~s}$, and after IRPL, most patients had a BUT of more than $10 \mathrm{~s}$.
Table 1. Tear breakup time (BUT)

\begin{tabular}{|l|c|c|c|c|}
\hline \multirow{2}{*}{ Time points } & \multicolumn{2}{|c|}{ Before } & \multicolumn{2}{c|}{ After } \\
\cline { 2 - 5 } & No. & $\%$ & No. & $\%$ \\
\hline Greater than $10 \mathrm{~s}$ & 2 & 3.1 & 56 & 87.5 \\
\hline Between 5 and $10 \mathrm{~s}$ & 48 & 75 & 6 & 9.4 \\
\hline Less than $5 \mathrm{~s}$ & 14 & 21.9 & 2 & 3.1 \\
\hline Total & 64 & 100 & 64 & 100 \\
\hline
\end{tabular}

The results of the chi-square Pearson test suggest dependence between the application of IRPL and BUT $(p=0.000<\alpha=0.05)$. The analysis of the standardized residuals shows that at each intersection there are significant differences at a $1 \%$ level of significance (corrected residuals $>2.57$ ), and by evaluating the sign it has been possible to detect that there is a significant increase after treatment, between a BUT greater than $10 \mathrm{~s}$ and significant decreases between 5 and $10 \mathrm{~s}$ and less than $5 \mathrm{~s}$.

Regarding the signs observed in the eyelid margin, blepharitis had a clear predominance before treatment, accompanied in order of frequency by eyelid margin irregularity, telangectasia and trichiasis. After IRPL there was a decrease in the occurrence of blepharitis and trichiasis; this decrease was less noticeable in the presence of eyelid margin irregularities and telangectasias, which were maintained with values very similar to those obtained before treatment (table 2).

Gland expression in the form of lumps predominated before treatment, followed by the expression of a cloudy liquid. After IRPL, more than half of the patients had clear liquid gland expression, and there were some cases in which granular expression persisted, although to a lesser extent. 


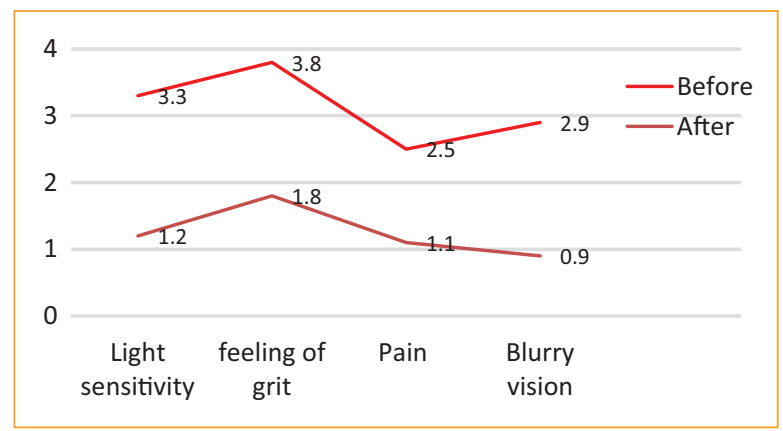

Figure 4. OSDI test: Symptoms (before and after IRPL).

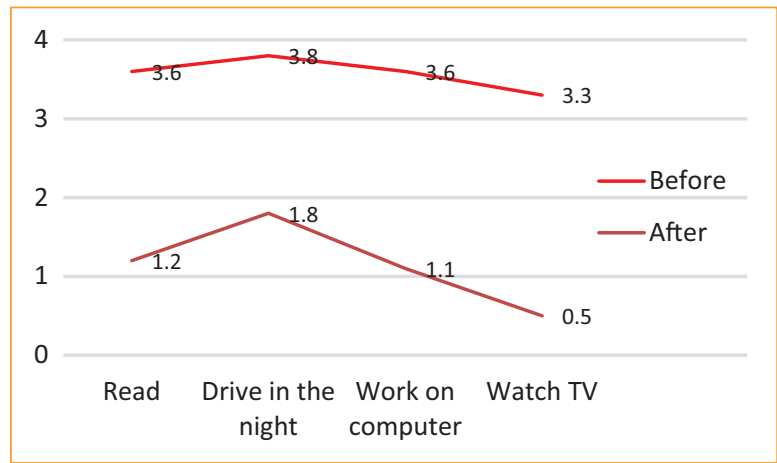

Figure 5. OSDI test: Daily activities (before and after IRPL).

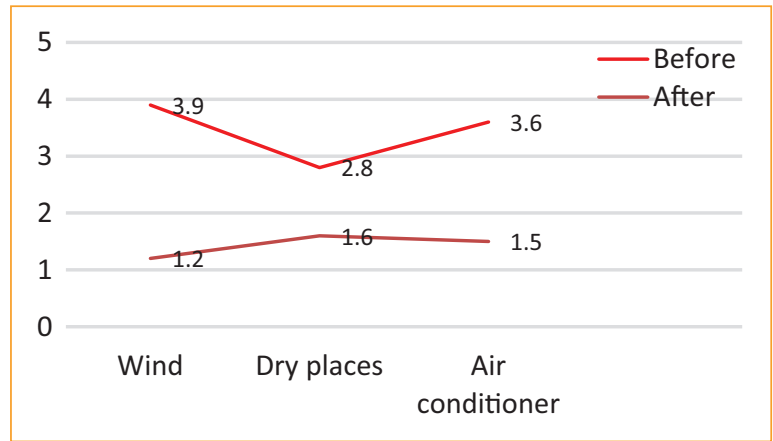

Figure 6. OSDI test: Situations (before and after IRPL).

The performance of an exact Fisher test reflects dependence on the categorical variables treated ( $p=0.000<\alpha=0.05$ ). An analysis of the corrected residuals suggests that this dependence is due to the positive influence of the highly significant increase $(\alpha=0.01)$ of cases with clear liquid presence after treatment was applied and the significant decrease $(\alpha=0.01)$ of cases with cloudy and granular liquid, with lumps. No significant difference was observed before
Table 2. Eyelid margin signs

\begin{tabular}{|l|c|c|c|c|}
\hline \multirow{2}{*}{ Signs } & \multicolumn{2}{|c|}{ Before } & \multicolumn{2}{c|}{ After } \\
\cline { 2 - 5 } & No. & Percentage & No. & Percentage \\
\hline Irregularity & 28 & 43.8 & 24 & 37.5 \\
\hline Telangectasia & 21 & 32.8 & 20 & 31.3 \\
\hline Blepharitis & 47 & 73.4 & 12 & 18.8 \\
\hline Trichiasis & 13 & 20.3 & 5 & 7.8 \\
\hline
\end{tabular}

Table 3. Characteristics of glandular expression

\begin{tabular}{|l|c|c|c|c|}
\hline \multirow{2}{*}{ Characteristics } & \multicolumn{2}{|c|}{ Before } & \multicolumn{2}{c|}{ After } \\
\cline { 2 - 5 } & No. & Percentage & No. & Percentage \\
\hline Clear liquid & 2 & 3.1 & 40 & 62.5 \\
\hline Cloudy liquid & 21 & 32.8 & 8 & 12.5 \\
\hline Granular, lumps & 38 & 59.4 & 14 & 21.9 \\
\hline Solid & 3 & 4.7 & 2 & 3.1 \\
\hline Total & 64 & 100 & 64 & 100 \\
\hline
\end{tabular}

Table 4. Pressure applied to induce glandular expression

\begin{tabular}{|l|c|c|c|c|}
\hline \multirow{2}{*}{ Pressure } & \multicolumn{2}{|c|}{ Before } & \multicolumn{2}{c|}{ After } \\
\cline { 2 - 5 } & No. & Percentage & No. & Percentage \\
\hline Soft & 16 & 25 & 52 & 81.3 \\
\hline Moderate & 42 & 65.6 & 10 & 15.6 \\
\hline Severe & 6 & 9.4 & 2 & 3.1 \\
\hline Total & 64 & 100 & 64 & 100 \\
\hline
\end{tabular}

and after treatment in the case of solid gland expression characteristic $(\alpha=0.05)$ (table 3$)$.

A predominance of moderate pressure performed for gland expression was observed. Before treatment, pressure applied was moderate in most eyes, after IRPL only a gentle pressure was necessary in most eyes (table 4).

Regarding the results of the OSDI test, a decrease in the score reported by the patients was obtained in the 3 areas included in the test after treatment, with a predominance of foreign body sensation, difficulty driving at night and discomfort before exposure to wind (Figs. 4, 5 y 6). 


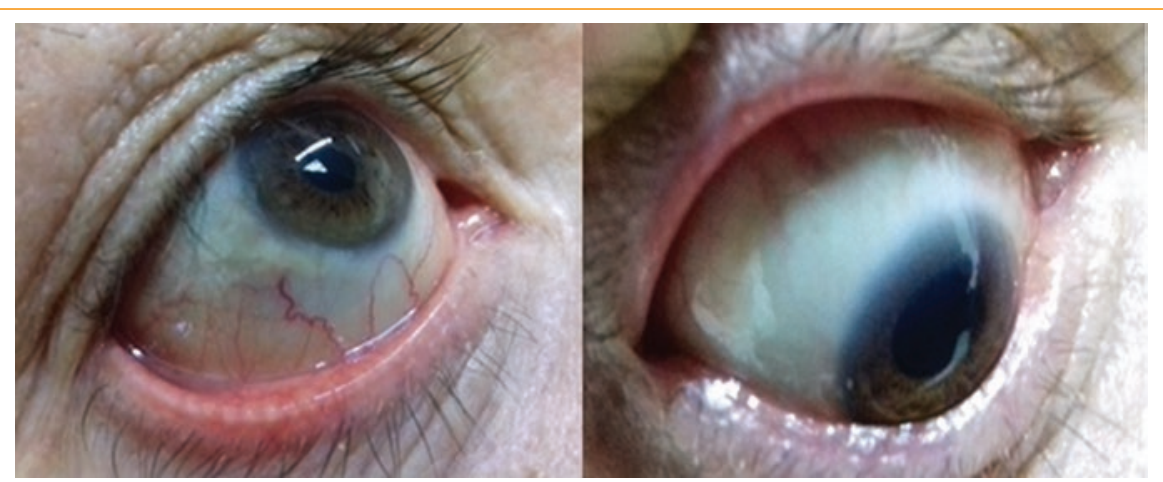

Figure 7. Patient treated with IRPL. In the left image, obtained after the second treatment session (day 15), the presence of a lacrimal meniscus of normal characteristics is observed. The right image was obtained after the third treatment session (day 45), which highlights the absence of conjunctival hyperemia.

\section{Discussion}

The subjective improvement of the patients studied, obtained by the OSDI test, shows a decrease in symptoms due to MGD, which is a common cause of evaporative dry eye, which affects almost $70 \%$ of the population in some parts of the world ${ }^{1}$. It manifests with ocular surface symptoms like burning, irritation, fluctuating visual acuity, red eye, among others (Fig. 7)

Frequently these symptoms, combined with ineffective treatment options, affect patients' quality of life. In MGD, glands may narrow; there is acinar atrophy and hyperkeratinization ${ }^{8}$. The meibum increases in viscosity, which promotes the proliferation of commensal bacteria. These bacteria secrete lipases that can alter the composition of the lipids in the meibum, and increase the level of esterified cholesterol (and its melting point), which further reduces gland production ${ }^{9-11}$.

Slit lamp signs of MGD may not be noticeable in the case of gland obstructive symptoms and, in other cases, may include obstructed or plugged meibomian gland orifices, along with thickening, irregularity, telangectasia, and hyperemia of the eyelid margin ${ }^{12,13}$.

In the patients studied, solidification of the secretions was observed in the most severe cases. Tear breakup time is reduced more frequently and the tear film is frequently contaminated by endogenous debris and foam ${ }^{11-13}$. Ultimately, Meibomian glands do not secrete enough oily layer for the tear film, which allows a higher evaporation rate of the underlying aqueous layer, which in turn leads to dry eye symptoms and inflammation of the ocular surface ${ }^{14,15}$.

The mechanism through which MGD signs and symptoms improve after treatment with IRPL remains a controversial issue and there are different hypotheses that support it. The proposed mechanisms include heat transfer, which softens the expression of the meibum ${ }^{16}$. However, a mechanism of this type would only induce short-term effects ${ }^{17}$.

In agreement with the recognized mechanism of action in the treatment of the skin in systemic rosacea ${ }^{18}$, it is possible that the thrombosis of the vasculature surrounding the meibomian glands could play a role in decreasing the local release of inflammatory mediators. In addition, the bacterial load in the eyelid margin and in the ocular adnexa could be directly affected by IRPL ${ }^{19}$.

All these mechanisms and/or hypotheses produce a significant increase in the amount of lipids on the tear film surface after treatment, which suggests that the meibum flow of the glands has been facilitated by the treatment with IRPL. In addition, the benefits seem to be cumulative, in such a way that after a course of three treatments for 45 days, improvements in the treated eyes are reported ${ }^{3-5}$. Another possibility is that IRPL has the potential to modify the mitochondrial production of reactive oxidative species, which has been implicated in dry eye ${ }^{20-23}$.

Other effects of IRPL have been documented, such as: photomodulation ${ }^{24}$, activation of fibroblasts and collagen synthesis ${ }^{25,26}$, coagulation and necrosis of Demodex ${ }^{27,28}$, modulation and secretion of anti-inflammatory molecules ${ }^{29,30}$, among others.

It would be important for future studies to perform treatment efficacy tests, compare with other groups of patients, and include other objective measures such as tear osmolarity. In addition, perform long-term studies that include more than three treatment sessions.

\section{Conclusions}

- IRPL application showed an increase in BUT in the majority of patients, above $10 \mathrm{~s}$, and a significant 
relationship was obtained between the procedure and the increase of this variable.

- A reduction in the frequency of eyelid margin characteristics related to MGD was observed after the procedure, as well as a need of lower pressure to achieve gland expression in most patients.

- Gland expression with a clear fluid was obtained in more than half of the sample, with a significant increase of patients in this group after IRPL.

- The procedure improved the condition in terms of dry eye symptoms, the possibility of carrying out daily activities and managing untoward environmental situations.

- This results show an improvement in both the clinical signs and symptoms of dry eye syndrome due to MGD after a course of three sessions of IRPL during a period of 45 days; however, future related long-term studies are required with this treatment.

\section{Ethical disclosures}

Protection of human and animal subjects. The authors declare that no experiments were performed on humans or animals for this study.

Confidentiality of data. The authors declare that they have followed the protocols of their work center on the publication of patient data.

Right to privacy and informed consent. The authors declare that no patient data appear in this article.

\section{Conflicts of interest}

The authors declare no conflicts of interest.

\section{Funding}

The authors declare that they did not receive funding for the research.

\section{References}

1. Lemp MA, Crews LA, Bron AJ, Foulks GN, Sullivan BD. Distribution of aqueous-deficient and evaporative dry eye in a clinic-based patient cohort. Cornea. 2012;31(5):472-78.

2. Qiao J, Yan X. Emerging treatment options for meibomian gland dysfunction. Clin Ophthalmol. 2013;7:1797-803.

3. Toyos R, Buffa CM, Youngerman S. Case report: Dry-eye symptoms improve with intense pulsed light treatment. Eye World News Magazine. 2005
4. Toyos R, McGill W, Briscoe D. Intense pulsed light treatment for dry eye disease due to meibomian gland dysfunction: a 3-year retrospective study. Photomed Laser Surg. 2015;33(1):41-6.

5. Craig JP, Chen YH, Turnbull PR. Prospective trial of intense pulsed Light for the treatment of meibomian gland dysfunction. Invest Ophthalmol Vis Sci. 2015;56(3):1965-70.

6. Vegunta S, Patel D, Shen JF. Combination therapy of intense pulsed light therapy and meibomian gland expression (IPL/MGX) can improve dry eye symptoms and meibomian gland function in patients with refractory dry eye: a retrospective analysis. Cornea. 2016;35(3):318-22.

7. Ding J, Sullivan DA. Aging and dry eye disease. Exp Gerontol. 2012:47(7): 483-90.

8. Obata H. Anatomy and histopathology of human meibomian gland. Cornea. 2002;21:S70-4.

9. Borchman D, Foulks GN, Yappert MC, Milliner SE. Differences in human meibum lipid composition with meibomian gland dysfunction using NMR and principal component analysis. Invest Ophthalmol Vis Sci. 2012;53:337-47.

10. Graham JE, Moore JE, Jiru X, Moore JE, Goodall EA, Dooley JS, et al. Ocular pathogen or commensal: a PCR-based study of surface bacterial flora in normal and dry eyes. Invest Ophthalmol Vis Sci. 2007;48:5616-23.

11. Mathers WD, Shields WJ, Sachdev MS, Petroll WM, Jester JV. Meibomian gland dysfunction in chronic blepharitis. Cornea. 1991;10:277-85.

12. Knop E, Knop N, Millar T, Obata H, Sullivan DA. The International Workshop on Meibomian Gland Dysfunction: report of the subcommittee on anatomy, physiology, and pathophysiology of the meibomian gland. Invest Ophthalmol Vis Sci. 2011;52:1938-78

13. Arciniega JC, Wojtowicz JC, Mohamed EM, McCulley JP. Changes in the evaporation rate of tear film after digital expression of meibomian glands in patients with and without dry eye. Cornea. 2011;30:843-7.

14. Bilkhu PS, Naroo SA, Wolffsohn JS. Effect of a commercially available warm compress on eyelid temperature and tear film in healthy eyes. Optom Vis Sci. 2014:91:163-70.

15. Jiang X, Lv, H Song H, Zhang M, Liu Y, Hu X, et al. Evaluation of the Safety and Effectiveness of Intense Pulsed Light in the Treatment of Meibomian Gland Dysfunction. J Ophthalmol. 2016;2016:1910694.

16. Nagymihályi A, Dikstein $S$, Tiffany J. The influence of eyelid temperature on the delivery of meibomian oil. Exp Eye Res. 2004;78(3):367-70.

17. Geerling G, Tauber J, Baudouin C. The international workshop on meibomian gland dysfunction: report of the subcommittee on management and treatment of meibomian gland dysfunction. Invest Ophthalmol Vis Sci. 2011;52(4):2050-64.

18. Schroeter CA. Haaf-Von Below S, Neumann HAM. Effective treatment of rosacea using intense pulsed light systems. Dermatol Surg. 2005;31:1285-9.

19. Farrell HP, Garvey M, Cormican M, Laffey JG, Rowan NJ. Investigation of critical inter-related factors affecting the efficacy of pulsed light for inactivating clinically relevant bacterial pathogens. J Appl Microbiol. 2010;108:1494-508

20. Chung H, Dai T, Sharma S, Huang YY, Carroll J, Hamblin M. The nuts and bolts of low-level laser (light) therapy. Ann Biomed Eng. 2012:40:516-33.

21. Wakamatsu TH, Dogru M, Matsumoto Y. Evaluation of lipid oxidative stress status in Sjögren syndrome patients. Invest Ophthalmol Vis Sci. 2013;54:201-10.

22. Hamblin MR, Huang YY, Sharma SK, Carroll J. Biphasic dose response in low level light therapy-an update. Dose Response. 2011;9:602-18.

23. Hamblin MR, Demidova TN. Mechanisms of low level light therapy. Photobiological Sciences Online; 2008. Disponible en: http://www.photobiology.info/Hamblin.html. Último acceso 21 julio de 2014.

24. Farivar S, Malekshahabi T, Shiari R. Biological effects of low level laser therapy. J Lasers Med Sci. 2014;5(2):58-62.

25. Cuerda-Galindo E, Díaz-Gil G, Palomar-Gallego M, Linares-García Valdecasas R. Increased fibroblast proliferation and activity after applying intense pulsed light 800-1200 nm. Ann Anat. 2015;198:66-7.

26. Goldberg D. Current trends in intense pulsed light. J Clin Aesthet Dermatol. 2012;5(6):45-53.

27. Prieto V, Sadick N, Lloreta J, Nicholson J, Shea C. Effects of intense pulsed light on sun-damaged human skin, routine, and ultrastructural analysis. Lasers Surg Med. 2002;30(2):82-5.

28. Kirn T. Intense pulsed light eradicates Demodex mites. Skin Allergy News. 2002;33(1):37.

29. Lee S, Park K, Choi J. A prospective, randomized, placebo-controlled, double-blinded, and split-face clinical study on LED phototherapy for skin rejuvenation: clinical, profilometric, histologic, ultrastructural, and biochemical evaluations and comparison of three different treatment settings. $J$ Photochem Photobiol B. 2007:88(1):51-67.

30. Taylor M, Porter R, Gonzalez M. Intense pulsed light may improve inflammatory acne through TNF- $\alpha$ down-regulation. J Cosmet Laser Ther. 2014;16(2):96-103. 